\title{
Research on operation scenario based aircraft power system architecture analysis and modelling
}

\author{
Chen Dongsheng ${ }^{1, \mathrm{a}}$, He $\mathrm{Yan}^{2}$ and Zhou Mengqian ${ }^{3}$ \\ ${ }^{1}$ Shanghai Aircraft Design and Research Institute, Shanghai, 201210, China \\ ${ }^{2}$ Shanghai Aircraft Design and Research Institute, Shanghai, 201210, China \\ ${ }^{3}$ Shanghai Aircraft Design and Research Institute, Shanghai, 201210, China
}

\begin{abstract}
Aircraft power system is a complex system consisting of the power generation system, the power management and distribution system, and the power consumption system, which accounts for the aircraft's major fuel consumption and emissions. This paper proposes a scenario-based comprehensive power requirement analysis and system architecture methodology in order to alleviate the risk of systems over-design and discoordination caused by traditional bottom-up load collection and individual system design. Starting from the operation scenario, system functions are identified and corresponding physical architecture and power loads are analysed. Given the complexity of operation scenarios and aircraft power system, model-based system engineering methodology is applied to the top-down aircraft power system architecture design. SysML tool is used to carry out to analyse the aircraft power system architecture during taxi scenario, which provides great advantages on model tracing and reuse.
\end{abstract}

\section{Introduction}

Civil aviation is one of the important industries in modern society, connecting people from different countries and continents together. It faces huge challenge of reducing energy consumption and carbon dioxide emissions, considering the expected average of $4.3 \%$ demand growth per year over the next few decades [1]. In 2009, all stakeholders of the aviation industry, including aircraft and engine manufacturers, airlines, airports, air navigation service providers and governments, committed to reduce global net aviation carbon emissions by $50 \%$ by the year 2050 relative to 2005 [2].

Jet fuel is consumed by the power system, which on the one hand to provide propulsion thrust to overcome aerodynamic resistance during flight, and on the other hand to provide secondary power for consumption of the whole aircraft onboard systems. Reducing aerodynamic drag is the most direct way to reduce fuel consumption, and there are many studies on how to design the optimal aerodynamic shape in the conceptual design stage [3]. Numerous numerical calculations and wind tunnel experiments are conducted to get optimal low-drag wing. In contrast, there is a lack of research and practise on the whole aircraft power systems architecture design at the initial stage, except most work on the individual system design such as electric system design. The current power loads analysis, such as electric load calculation, is mainly collected from users by the bottom-up approach. This inverse statistical analysis method on the one hand tends to cause a large gap between the design load with the actual load, on the other hand ignores coordination with other energy systems [4][5][6].

This paper proposes a scenario-based comprehensive power requirement analysis methodoly including electrical power, hydraulic power, and pneumatic power. Based on model-based system engineering concepts, the aircraft power system architecture analysis and modelling are carried out from a global perspective.

\section{Scenario-based power load analysis}

Civil aircraft airborne systems are generally categorized using Air transportation Association(ATA) chapter numbers, where there are more than twenty powerrelated systems. In order to better analyze the aircraft energy flow, the whole aircraft power system can be divided into three parts (see Figure 1), including the power generation system, the power management and distribution system, and the power consumption system.

Power generation system: generating thrust or secondary power for onboard equipment, including engines, auxiliary power unit(APU) and ram air turbine (RAT).

Power management and distribution system: regulating and distributing the secondary power to onboard equipment, including electrical power system(EPS), hydraulic power system(HPS) and pneumatic power system(PPS).

Power consumption system: consuming the secondary power, including electrical power loads(EPL), hydraulic power loads(HPL) and pneumatic power loads(PPL).

$\overline{{ }^{a} \text { Corresponding author: chendongsheng } @ \text { comac.cc }}$ 


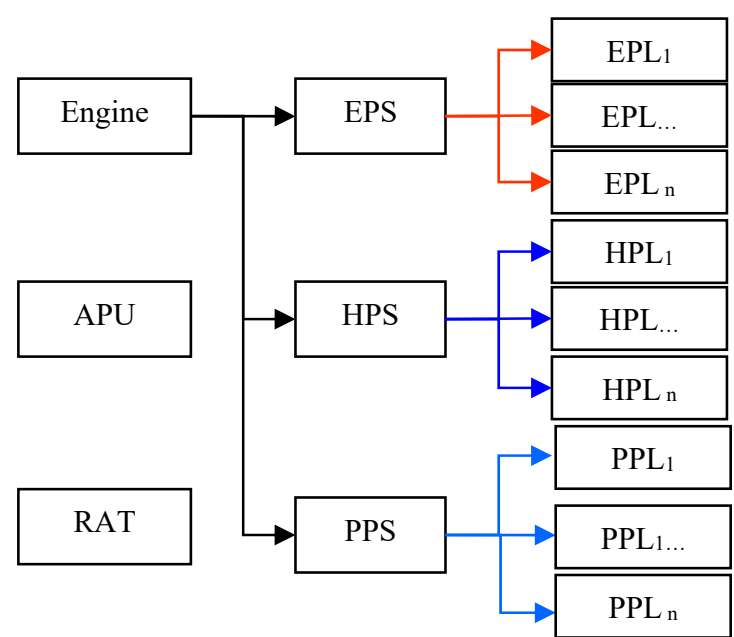

Figure 1. the overview aircraft power system based energy flow

There are nearly a thousand powers loads on the aircraft. In order to solve many problems caused by reverse engineering load statistics, a top-down methodology of power requirement analysis based on operating scenarios is proposed in this paper. Figure 2 shows the four main processes of forward power requirement analysis.

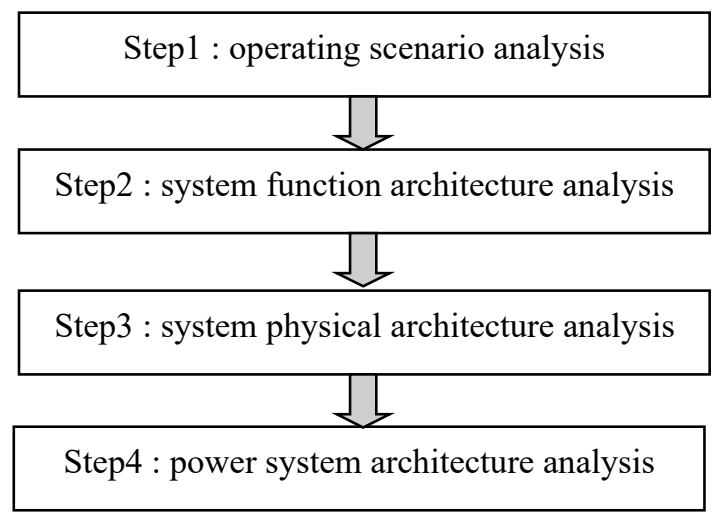

Figure 2. Aircraft power requirement analysis methodology based on operating scenarios

\subsection{Aircraft operating scenario}

The mission of commercial aircrafts is to move the passengers from point $A$ to point $B$ and ensure the safety and comfort of the persons on board during the entire flight. Considering the flight time, aircraft status and external environment, there are three typical types of scenarios, including normal operation scenarios, specific operation scenarios and failure operation scenarios.

Normal operation scenarios are the baseline flight which is divided into seven flight phases according to ICAO Phase of Flight Definition and Usage Notes, as presented in Table 1 . Since the task performed by the aircraft stakeholders (flight crew, flight attendants, passengers) in different flight phases are different, the functions supporting related missions are also different, and the power required to achieve this function will also change. For instance, the catering service is only performed after the aircrafts fly to a certain height in Enroute phase and the corresponding kitchen heating can perform, while such function will not be used in other phase (such as taxi phase).

Table 1. flight phases division and definition of normal operation scenarios

\begin{tabular}{|c|c|}
\hline Flight phases & Phases definition \\
\hline Standing & $\begin{array}{c}\text { Prior to pushback or taxi, or after } \\
\text { arrival, at the gate, ramp, or parking } \\
\text { area, while the aircraft is stationary. }\end{array}$ \\
\hline Taxi & $\begin{array}{c}\text { The aircraft is moving on the } \\
\text { aerodrome surface under its own } \\
\text { power prior to takeoff or } \\
\text { after landing. }\end{array}$ \\
\hline Takeoff & $\begin{array}{c}\text { From the application of takeoff power, } \\
\text { through rotation and to an altitude of } \\
35 \text { feet above runway elevation. }\end{array}$ \\
\hline Initial climb & $\begin{array}{c}\text { From the end of the Takeoff subphase } \\
\text { to the first prescribed power } \\
\text { reduction, or until reaching 1,000 feet } \\
\text { above runway elevation or the VFR } \\
\text { pattern, whichever comes first. }\end{array}$ \\
\hline Enroute & $\begin{array}{c}\text { From completion of Initial Climb } \\
\text { through cruise altitude } \\
\text { and completion of controlled descent } \\
\text { to the Initial Approach Fix }\end{array}$ \\
\hline Approach & $\begin{array}{c}\text { From the Initial Approach Fix to the } \\
\text { beginning of } \\
\text { the landing flare }\end{array}$ \\
\hline randing & $\begin{array}{c}\text { From the beginning of the landing } \\
\text { flare until aircraft exits the landing } \\
\text { runway, comes to a stop on the } \\
\text { runway }\end{array}$ \\
\hline
\end{tabular}

Specific operation scenarios are where aircraft operation capability are increased under specific environments and conditions, such as polar operation, low visibility operation, etc. Compared with normal operation scenarios, the task complexity is higher and the corresponding functional performance requirements will increase, which in turn energy demand may increase.

Failure operation scenarios are degraded operation mode because of the aircraft systems fault or error. For power analysis, key failure scenarios are engine failure, generator failure, etc. Single engine failure is often the design point of traditional aircraft hydraulic system and power system design. In this case, it shall be studied which functions are allowed to be downgraded and which cannot.

\subsection{From scenario to power loads}

Function is system behavior and ability to support task realization. In order to achieve all tasks in a certain scenario, a set of functions is often required. In order to achieve a certain function, a set of physical components is often required.

From function perspective, the relationship between scenarios tasks and system physical architecture can be 
well established. Taking the ground taxi scenarios as an example, the main ground tasks are ground steering and braking(see Table 2), maintaining a comfortable cabin environment, make preparation for takeoff etc. When aircraft taxiing in night, external light is provided.

Table 2. the simplified task-function- onboard systems-power loads lists during ground taxi

\begin{tabular}{|c|c|c|c|c|}
\hline Scenarios & Tasks & Functions & $\begin{array}{c}\text { Onboard } \\
\text { Systems }\end{array}$ & $\begin{array}{c}\text { Power } \\
\text { loads }\end{array}$ \\
\hline \multirow{7}{*}{ Taxi } & $\begin{array}{c}\text { Ground } \\
\text { steering }\end{array}$ & $\begin{array}{c}\text { Provide } \\
\text { steering }\end{array}$ & $\begin{array}{c}\text { Landing } \\
\text { gear } \\
\text { system }\end{array}$ & $\begin{array}{c}\text { Steering } \\
\text { actuator }\end{array}$ \\
\cline { 2 - 5 } & $\begin{array}{c}\text { Ground } \\
\text { braking }\end{array}$ & $\begin{array}{c}\text { Provide } \\
\text { braking }\end{array}$ & $\begin{array}{c}\text { Wheel } \\
\text { brakes } \\
\text { system }\end{array}$ & $\begin{array}{c}\text { Braking } \\
\text { actuator }\end{array}$ \\
\cline { 2 - 5 } & $\begin{array}{c}\text { Using the } \\
\text { external } \\
\text { light }\end{array}$ & $\begin{array}{c}\text { Provide } \\
\text { External } \\
\text { Lighting }\end{array}$ & $\begin{array}{c}\text { Light } \\
\text { system }\end{array}$ & $\begin{array}{c}\text { External } \\
\text { lights }\end{array}$ \\
\hline
\end{tabular}

\section{Model based aircraft power system architecture analysis during taxi}

Model based systems engineering is a formalized methodology supporting scenario analysis, function analysis and system architecture analysis for complex systems. Compared with traditional document-oriented working methods, the application of model-driven methods brings many advantages, including model tracing, model reuse, and multidisciplinary communication [7]. Aircraft power system analysis involves complex scenarios and numerous onboard systems. In order to improve the correlation and traceability of various activities and speed up the iterative efficiency of power load analysis, SysML tool is used to carry out model-based power requirement analysis. Based on system modelling methodology, the operation scenario modelling is carried out through use case diagrams and activity diagrams, system function architecture analysis through internal block diagrams(IBD), system physical architecture analysis through IBD, and aircraft power system architecture through IBD and block definition diagram(BDD) [8]. This paper selects the ground taxi scenario as a case to model the entire energy system analysis process.

\subsection{Operating scenario modelling}

Figure 3 is a use case diagram of the three-dimensional operation scenario of an aircraft, which expresses the typical operating scenario that shall be considered in power requirement analysis. During ground taxi, the activities of various stakeholders are captured through an activity diagram. Flight phases of normal operation scenarios is depicted in Figure 4. The tasks and behaviours of crew, flight attendants, passengers during taxi are represented in the different lanes of Figure 5, while in the aircraft lanes the system functions are identified to support other lane tasks.

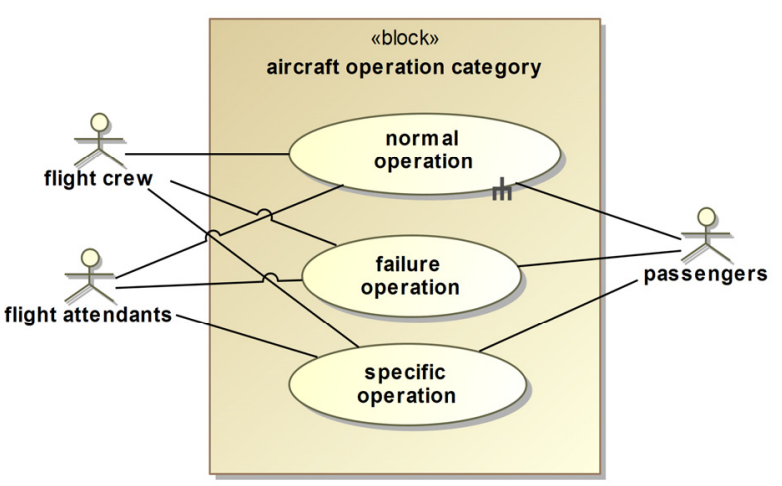

Figure 3. use case diagram of typical operating scenario

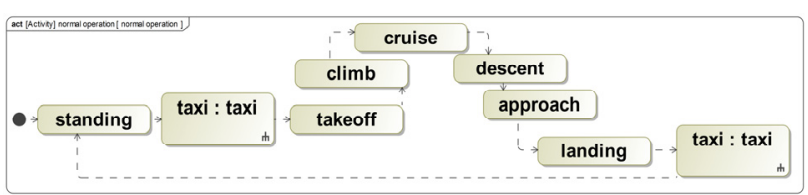

Figure 4. flight phases of normal operation scenarios of activity diagrams

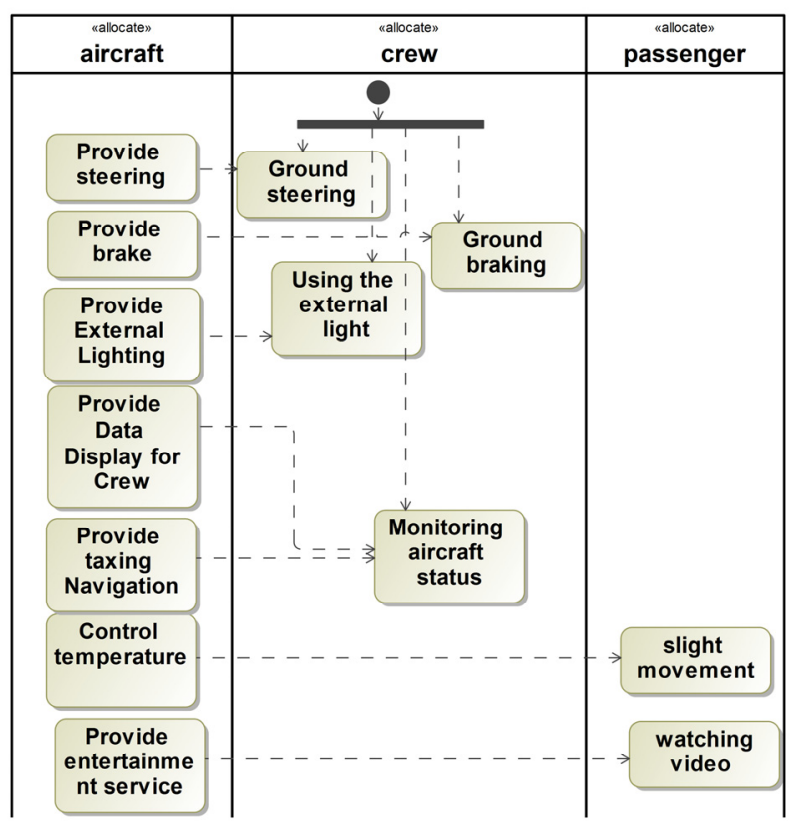

Figure 5. tasks and behaviours in taxi of activity diagrams

\subsection{Function architecture modelling}

Based on the above scenario analysis, the energy flow between the system functions is depicted in the internal block diagrams (see Figure 6). Provide Fuel function provides the required fuel to Provide Primary Power function, then Provide Primary Power function provides mechanical power to Provide and Distribute Electrical Power function and Provide and Distribute Hydraulic function. Provide and Distribute Electrical Power function and Provide and Distribute Hydraulic function provide secondary power to system function (such as brake function) to support taxi tasks. 


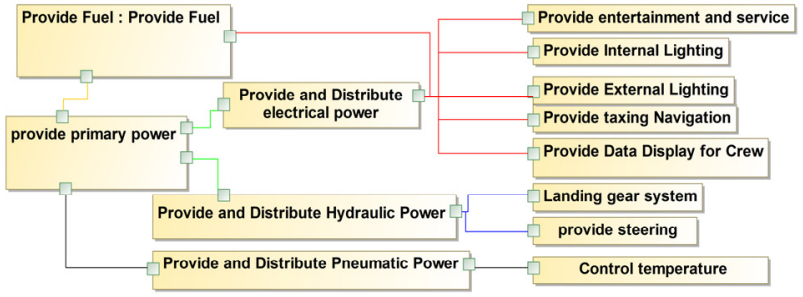

Figure 6. function architecture of IBD

\subsection{System physical architecture modelling}

Each system function in the figure above is implemented by on-board systems, for example, the temperature control function is implemented by environmental control system. Based on the functional architecture shown above, the corresponding physical architecture is shown in the Figure 7.

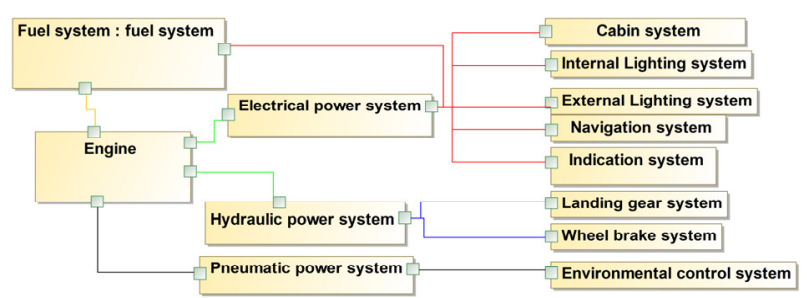

Figure 7. System physical architecture of IBD

\subsection{Aircraft power system architecture modelling}

The onboard system uses a variety of energy sources to perform the functions involved, and the relevant power loads are identified to support functions running. The following diagram of Figure 8 depicts the aircraft energy system interface diagram under the taxi scenario, which shows the energy flows. By organising the power generation system, the power management and distribution system, and the power consumption system, the aircraft power system architecture decomposition diagram is formed as shown in Figure 9.

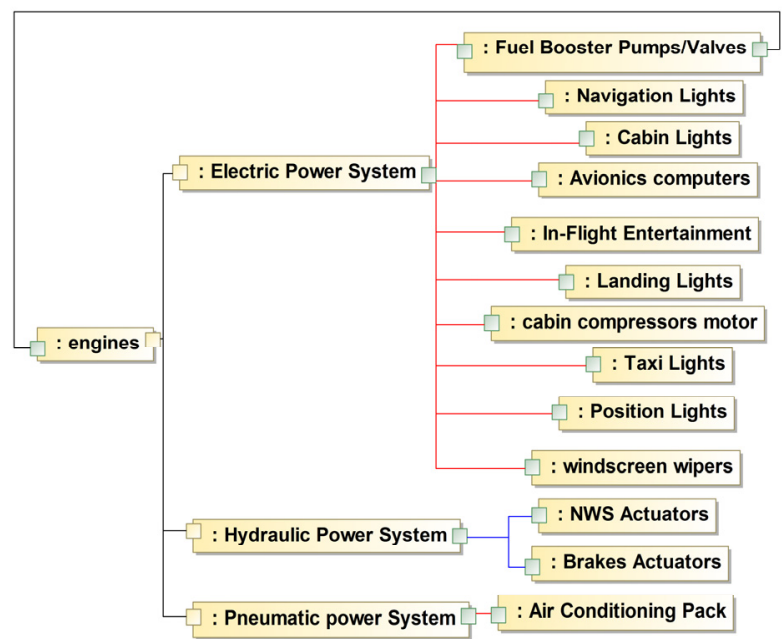

Figure 8. aircraft power system interface architecture of IBD

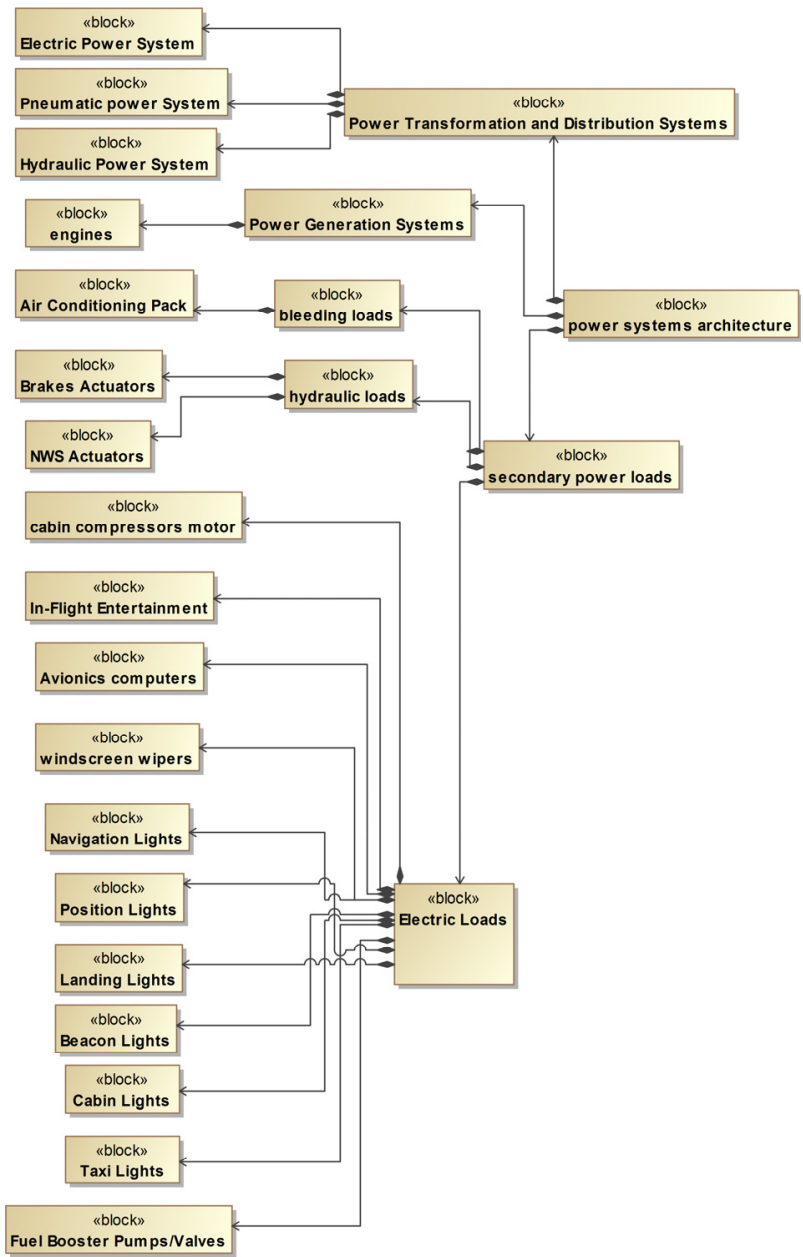

Figure 9. aircraft power system decomposition architecture of BDD

\section{Conclusion}

In order to lower the risk of systems over-design and discoordination caused by traditional inverse statistical analysis method and individual system design, a scenario-based comprehensive power requirement analysis and system architecture methodology is established in this paper. Three typical types of scenarios are introduced, and power loads are precisely analysed through system functions-physical architecture approach in a certain scenario. The approach is of great significance in reducing power system over-design. Meanwhile, SysML tool is used in aircraft power system architecture design in taxi scenario in this paper. It is proved to be a great advantage over traditional document-oriented working methods in terms of fast iteration and correlation traceability.

\section{References}

1. ICAO.(2021) Future of Aviation. online: https://www.icao.int/Meetings/FutureOfAviation/Pa ges/default.aspx, May 4, 2021.

2. ICAO. (2004) Aircraft Technology Roadmap to 2050. 
3. Boone, Tom R. and A. Striz. "Optimization of Aircraft Configuration for Minimum Drag." (2010).

4. Hanke, Susan. "A model-based methodologyfor integrated preliminary sizing and analysisof aircraft power system architectures." (2008).

5. Seresinhe, R. and C. Lawson. "Electrical load-sizing methodology to aid conceptual and preliminary design of large commercial aircraft." Proceedings of the Institution of Mechanical Engineers, Part G: Journal of Aerospace Engineering 229 (2015): 445 466.

6. Scholz, Dieter. "Computer Aided Engineering for the Design of Flight Control and Hydraulic Systems." SAE transactions 105 (1996): 203-212.

7. Maier, Anja M. et al. "DS 87-3 Proceedings of the 21st International Conference on Engineering Design (ICED 17) Vol 3: Product, Services and Systems Design.” (2017).

8. Balmelli, L.. "The Systems Modeling Language for Products and Systems Development." J. Object Technol.6(2007):149-177. 